\title{
INDIVIDUALIZATION OF LANGUAGE LEARNING THROUGH THE CASSETTE RECORDER
}

\section{by Michael Agatstein}

When I was first invited by Mr. Dodge to address your organization, I was truly flattered. After all, coming from the high school level, where every teacher is a lab director, technician and all around babysitter, I wondered what I really could offer such a group as this that would be meaningful.

After my conversation with Mr.Dodge, I had serious misgivings, since all my recent experimentation with cassette recorders came about as the direct result of my total and complete disillusionment with the language lab as conceived today; its goals, its concepts, its mechanics and its administration.

It was about four years ago that I completely stopped taking my classes to the lab. This, in spite of the fact that I have always been fascinated by this electronic marvel and always felt that if properly handled it could be the language teacher's greatest aid in the learning of a foreign language. My major objection to the lab could be summarized as follows:

Because of structuring, and the number of students involved, the lab forced students to react in lock-step fashion, with little or no concern for individual differences; forcing them to react to complex language patterns, in many cases too difficult, unfamiliar, or just plain dull.

The students quickly became parrots, mimicking without understanding, and frequently reinforcing errors.

The software prepared commercially for labs was inadequate. All it did in many cases was transfer the dullness and tedium of the classroom to the language lab and the lab compounded this dullness by the impersonality of the tapes and the machines and the physical surroundings.

Finally, all this was compounded by the frequent breakdown of the machines brought on by the rapid aging of the equipment, and the busy little fingers of bored students.

1A speech delivered at the AECT/NALLD Seventh Annual Business Meeting, March 23, 1971, Philadelphia, Pennsylvania. 


\section{Learning Through Cassette Recorder}

In exasperation, I abandoned the lab; and yet I was bothered, be. cause I felt that the lab tape recorder, if properly used, could lead to the true individualization of learning without going to the fantastic expense of a one to one relationship. Therefore, last spring I prepared an outline for an advanced French conversation course; and with the active support of my coordinator, Mrs. Feindler, "sold" the idea to administration. I spent almost the entire summer preparing the program in detail, following the principles of what I considered a true teaching tape, namely:

a. It should not talk down to, it should talk with.

b. It should be natural, cough, chuckle, hesitate, hum, etc.

c. It should be humorous-corny if necessary.

d. It should be built around variety.

e. It should use music and sounds, for that basically is what the tape recorder can do best.

f. And, finally perhaps most importantly, it should involve the students in active participation.

Five master tapes were duplicated on cassettes for each student in the class; each cassette was accompanied by mimeographed sheets relating to work that the cassette demanded.

Let me first give you a bit more background about the course itself. The major purpose of the course was to create an atmosphere that would enable students to develop an ability to comprehend with relative facility and to speak reasonably fluently on a wide range of topics of current and immediate interest.

To create this atmosphere, the course was structured as follows:

a. It was to be an elective, open to seniors who had finished their high school language requirements.

b. It was to be limited to 15 .

c. It would use a pass-fail system.

d. It would be a one semester course.

e. It would be so run that students would feel no restrictions to free conversation.

To supply subject matter for discussion, the course included:

a. A textbook to supply vocabulary and act as a starting point.

b. French newspapers and magazines in their original editions.

c. A wide assortment of tapes, radio broadcasts and films.

And then-to add one extra innovation, never used before to my knowledge by any other public language course in the United Statesthe students were required to purchase a cassette tape recorder to be used by them exclusively at home.

The class spent one week, for example, studying and talking about a certain phase of French and American life, using the book or 
a newspaper as a guide. At the end of the week's discussion in class, the homework assignment was to prepare a 10-15 minute cassette containing the following: First, a discussion of any aspect of the work done that week in class (using the new vocabulary acquired that week). This was followed by the reading of a poem, an article, or a short story which I supplied (for pronunciation correction purposes). It concluded with a free discussion on their part, of any topic of interest to them, from music to sports, from philosophy to current events, from personal problems to school problems.

When the students handed in their cassettes I took them home and listened to them, answering each student personally on the cassette, correcting his pronunciation and grammar, giving him drills and exercises on those points I felt that he was weakest. I also took this opportunity to comment on his classwork. I would encourage him, point out his failings, show him how to improve himself, and then respond to any of the problems or questions he may have raised.

At the end of the following week's work in class, the student was given as homework, a cassette which I had prepared. It was a 30 minute structured cassette, which presented to the student about eight different native speakers, in a fashion that would make the student respond at home, at his leisure, orally and/or in writing. The following is an idea of what some of the tapes contained:

1. The students were given a radio broadcast, taken directly from a short wave radio, of a 2 minute or 3 minute duration, followed by questions I added to the tape, that they had to respond to, either orally, in writing or both, using the mimeographed sheets that were provided. These sheets also contained necessary vocabulary.

2. Each tape also contained songs sung by popular French singers, either American songs in French or the latest rock and roll directly from France. The songs were used for entertainment, or for dictation purposes. The students were asked to identify as many words as possible from the song or.were asked specific questions relating to the song.

3. Each tape also contained a short dictation (and by the way, the text of this dictation was given right on the mimeographed sheet but in upside down fashion so the student couldn't look at it directly).

4. Another frequent exercise used on the tape was a grammar drill. It was, however, presented in novel fashion. For example, to teach and test the use of the proper prepositions with countries, excerpts of popular music from various coun. 
tries were played and the student would have to respond with: Je vais en Italie-or-Je vais au Mexique, etc.

5. Each tape also contained either skits, vocabulary games, aural comprehension quizzes, jokes, or puzzles, etc.

I prepared a total of five cassettes, and five cassettes were prepared by the students. Mine lasted 30 minutes, but the time required by the students varied, either from one to three hours, depending on how hard they worked, what level they came from, how good students they were. There was no pressure, nothing to hand in by way of written work; but they did it for the fun of doing it. The basic advantages of the cassette homework assignments, both mine and theirs, were many. First of all, it personalized instruction to a point never achieved before. Secondly, the student could go as fast or as slow as he wanted, replay anything he didn't understand as many times as he saw fit. It allowed for- originality and for creativity on the part of the student, yet, in a structured and meaningful fashion. Finally, instead of discouraging a student, as we frequently do by constant class correction, by the use of the cassette we were able to correct errors on a person to person basis with no one listening in to embarrass the student.

Did I achieve my purpose? It's very, very hard to judge results in a conversation course. There are no real tests available, but I did ask the student to prepare, in English, an evaluation of the course. In essence, and without exception, all the students felt that the course was a wonderful learning experience; it helped them in a practical manner to improve their speaking ability, no matter what their level. Good students, already able to speak well, enlarged and enriched their vocabularies; poorer students lost their fear of speaking and learned to express themselves on topics they never would have dared to undertake. All were delighted with the cassettes; the words "I enjoyed the course" seem to be a common theme. Not only did they enrich their knowledge of French and things French, but their interest in other areas was stimulated through the medium of discussion, and most students recommended that the course be extended to a full year and that it replace the regular literature course.

There is also another aspect that I judge to be even more important than the students' evaluation, and that was their own class reaction and the quality of their cassettes. First, the cassette was supposed to average 10 minutes. Without exception, the students prepared tapes that lasted anywhere from 20 to 30 minutes. Second, students who were tongue-tied in class opened up on the cassettes. In the comfort of their homes they were able to relax and unbend. Third, their creativity was truly remarkable. Let me give you some ideas of what they did with their portable cassette recorders: 
1. One student took his recorder to a concert at Philharmonic Hall and recorded part of the concert with comments on the players, music and audience.

2. Another went to the local railroad station and recorded arrivals and departures of trains, with appropriate comments about the travellers.

3. Another played a background recording of the sounds at a Cape Kennedy moon shot with appropriate comments.

4. One student played the music of "Peter and the Wolf" and told the entire story in French along with the music.

5. Another student sang a beautiful French song and accompanied herself on the guitar.

6. One student even dared to give me a 15 minute discussion on the theories of Pascal, and when I responded with some opposite points of view, carried on the discussion in his next cassette.

7. And, finally, personal problems-problems of teenagers in love, problems of the home, of the school-questions to the teacher about his own personal life, opinions that the students requested of the teacher, about Vietnam, drugs, etc.

All were discussed by students and commented on by the teacher. Although I never gave any marks, I kept a record on the cassettes the students prepared. There was a general improvement from the first cassette to the last. I personally felt that the course had achieved its major goals.

What does this mean in essence for the language lab? Well, let me present a recommendation I have made to our administration based on my experiences with the cassette tape recorder:

First, the language learning lab should be totally converted to a cassette set-up, allowing for individual listening and recording with the dual track system, a central tape-cassette console without most of the controls for listening in to individual students.

Secondly, it should be installed in a room with carpeted flooring, attractive surroundings and the elimination of the maze-like booths so prevalent today.

Third, materials should be created for specific purposes and specific levels with each selection on an individual cassette so that the student can listen at any time to whatever tape he wishes or is assigned to-individually and not necessarily on a group basis.

Fourth, the lab thus becomes, not a drill center but a language learning resource center containing a variety of cassettes on all 


\section{Learning Through Cassette Recorder}

levels that students can draw on at their leisure, listen to and react to, assigned or unassigned.

I thus visualize a resource center containing:

1. Cassettes, each one focusing on one specific grammatical con. cept, explaining humorously, drilling, but not ad nauseum, and quizzing not testing. A particular grammatical point could be introduced with a joke, explanation given in English with ex. amples in French, and then a short drill, followed by a short song, the whole thing to last not more than 10-15 minutes. This could be done on at least 30 basic French grammatical points.

2. Cassettes on French classical music, French opera, and French popular music. Especially French popular music with words to go along so the students can follow, encouraging them to sing along.

3. A whole series of cassettes treating various French authors, with readings from their writings, with accompanying sheets and questionnaires perhaps.

4. Cassettes of short stories, short plays, famous historical figures.

5. Dual track pronunciation cassettes, using material of current interest.

6. Aural comprehension cassettes of the examination type frequently used.

7. Cassettes similar to the ones I prepared for my conversation course.

By becoming a language resource center available at all times on an assigned or unassigned basis by creating the proper physical atmosphere, and supplying a purposeful software, a new lab will be created. And, if you add to this the new video cassettes soon to come on the market, I think that the language learning resource center will have a new rebirth.

ABOUT THE AUTHOR:

Michael Agatstein is a member of the staff of Wheatley School, Old Westbury, New York. 